Revista de Filosofía

ISSN: 0034-8244

https://dx.doi.org/10.5209/resf.64590

\title{
Una ruta de Kant a Hegel. Destino: ¿McDowell?
}

\author{
Rafael Aragüés Aliaga ${ }^{1}$
}

Recibido: 4 de junio de 2019 / Aceptado: 9 de julio de 2020

Resumen. El presente artículo trata sobre la relación entre el pensamiento de John McDowell y la obra de Hegel. La idea fundamental es exponer la línea argumental que va, en el marco de la filosofía analítica, desde una posición kantiana a una hegeliana. El punto clave se sitúa en la lectura de la deducción de las categorías vista a la luz de la crítica de Wilfrid Sellars al mito de lo dado. A partir de ahí, el objetivo es discutir si esta ruta de Kant a Hegel tiene como destino la filosofía de McDowell contrastando la filosofía de estos dos últimos: repensar el concepto de idealismo y la relación entre experiencia y filosofía desde ambos autores, Hegel y McDowell, tanto en sus similitudes como en sus discrepancias.

Palabras clave: Hegel; McDowell; deducción trascendental; idealismo; experiencia.

\section{[en] A route from Kant to Hegel. Destination: McDowell?}

\begin{abstract}
This paper focuses on the relation between the thinking of John McDowell and Hegel's philosophy. The key issue is to explain the main argument that, within the framework of analytic philosophy, goes from a Kantian to a Hegelian position. Kant's transcendental deduction of categories and its interpretation, seen from the perspective of Wilfrid Sellar's criticism to the Myth of the Given, is the key point. Departing from that, my aim is to discuss whether this route from Kant to Hegel finally ends at John McDowell's philosophy by contrasting the philosophy of these last two: to rethink the notion of idealism and the relationship between experience and metaphysics on both authors, Hegel and McDowell, in both their similarities and in their differences.
\end{abstract}

Keywords: Hegel; McDowell; transcendental deduction; idealism; experience.

Sumario: 1. Introducción; 2. Kant, Hegel y la deducción de las categorías; 3. La inconstricción del pensamiento; 4. La experiencia y el libre movimiento del concepto; 5 . Experiencia y sistema; 6. Conclusión; 7. Referencias bibliográficas.

Cómo citar: Aragüés Aliaga, R. (2021): “Una ruta de Kant a Hegel. Destino: ¿McDowell?”, en Revista de Filosofia 46 (2), 355-371.

\footnotetext{
1 Doctor en Filosofía por la Ruprecht-Karls-Universität Heidelberg rafael.aragues@gmail.com
} 


\section{Introducción}

La filosofía analítica de las últimas décadas tiene entre una de sus principales influencias la obra de Wilfrid Sellars. El ensayo de Sellars titulado Empiricism and the Philosophy of Mind es una de las obras de filosofía analítica contemporánea que más han sido discutidas y siguen siéndolo a día de hoy. No en vano, pues esta obra, junto con el famoso artículo de O.W. Quine, Two Dogmes of Empiricism, constituye una verdadera revolución para la filosofía anglosajona contemporánea. Y constituye una revolución porque Empiricism and the Philosophy of Mind ataca los cimientos del padre de la filosofía analítica. Si su madre es la lógica formal, y sobre todo, el logicismo, su padre es sin duda el empirismo. Contra éste está dirigido el ensayo de Sellars, a saber, contra el fundamento mismo del empirismo. Porque Sellars descubre en el presupuesto más básico del empirismo una ilusión de nefastas consecuencias para éste. El empirismo, a fin de cuentas, se basa en los hechos, en lo dado. Pero en lo dado descubre Sellars más bien un mito. Lo dado es un mito porque no existe como tal, porque no hay nada parecido a una materia puramente sensible, independiente y previa a toda formación conceptual, huelga decir ya, por supuesto, algo así como objetos que se den pura y simplemente a los sentidos. Todo aquello supuestamente dado, aquello que está aquí y ahora, que vemos y tocamos, implica, si es que ha de ser parte de un razonamiento, la base de un juicio o el fundamento de una teoría, implica, digo, un entramado conceptual que requiere un aprendizaje que engloba desde conocer las condiciones estándar de observación hasta poseer una serie de conceptos generales con los que identificar y conocer cualquier hecho concreto, cualquier objeto dado, cualquier impresión o dato empírico por simple que sea.

La consecuencia en el panorama analítico de esta atinada crítica al mito de lo dado es un nuevo y especial interés por dos filósofos continentales clásicos. El primero de ellos es, sin duda, Kant, y por razones evidentes. Pues fue Kant quien a finales del siglo dieciocho ya planteó, a su manera, algo parecido a lo que Sellars plantea en Empiricism and the Philosophy of Mind: que intuiciones sin concepto son ciegas, y que como condición de posibilidad del conocimiento empírico, es decir, de la experiencia, no basta simplemente la sensibilidad, esto es, el ser capaz de observar cómo es la realidad, el tener la gracia de estar abierto a lo dado. Sólo con eso no vale, porque lo que la sensibilidad aporta es, en sí y por sí solo, un caos amorfo de datos. Condición de posibilidad de la experiencia es también y en la misma medida el entendimiento, con sus conceptos puros y sus principios. La experiencia, incluso la observación más inmediata, es siempre experiencia entendida. La vuelta a Kant desde la filosofía analítica viene así motivada por el interés de pensar el conocimiento humano sin caer en el mito de lo dado.

El segundo de estos filósofos continentales a los que vuelve la filosofía analítica, por razones algo más complicadas y dispares, es Hegel. La vuelta a Hegel es en este caso polisémica y multifactorial. Se vuelve a él, a la postre, de muchas y diferentes maneras y con diversas motivaciones. Pero creo que podemos identificar con claridad al menos una línea de fuga hacia Hegel en la discusión analítica contemporánea abierta a partir de la obra de Sellars. ${ }^{2}$ La desmitificación de lo dado no significa para Sellars solamente un ataque frontal al empirismo. Significa también, en el fondo, un

2 Para una contraposición de las posiciones metafísicas de Hegel y Sellars, siendo Hegel presentado como un monismo holístico frente al fisicalismo de Sellars, véase deVries (2019). 
ataque igualmente frontal a la a su juicio errónea metáfora de la fundamentación del conocimiento empírico, según la cual este conocimiento descansa sobre proposiciones empíricas que describen hechos del mundo. Esta metáfora, la metáfora del elefante que descansa sobre la tortuga, es según Sellars, misleading, pero sobre todo, es una concepción que ya no es posible sostener, toda vez que uno es consciente de que aquello puramente dado sobre lo que ha de reposar todo el edificio de las ciencias es en realidad un mito. Para Sellars, hay que abandonar esta imagen y adoptar una concepción del conocimiento racional como una empresa que está en constante autocrítica, corrigiéndose a sí misma. ${ }^{3}$

Es esta necesidad de concebir el conocimiento racional como una empresa circular, que se autofundamenta y se corrige constantemente, lo que lleva a la relectura de Hegel. Esta motivación está presente en uno de los mayores filósofos actuales del mundo anglosajón y experto en Kant y Hegel, a saber, en John McDowell. En el libre movimiento del concepto, que se desarrolla a lo largo de todo el sistema de la filosofía de Hegel - habría que decir, más bien, el libre movimiento de la Idea - ve McDowell la evolución de la investigación empírica, el desarrollo de las ciencias, un desarrollo que es esencialmente una empresa autocrítica.

Sellars, Kant y Hegel son, de esta manera, las tres estaciones en el camino a un nuevo pensamiento superador del empirismo, pero también superador de las limitaciones de la filosofía trascendental kantiana. Si el proyecto de Sellars era llevar la filosofía analítica de Hume a Kant, ${ }^{4}$ el proyecto de McDowell puede entenderse como el tránsito de la misma filosofía analítica de Kant a Hegel. Todo ello, por supuesto, siempre partiendo y moviéndose dentro de los problemas y los presupuestos tradicionales de la filosofía analítica, de cuyo marco McDowell ni sale ni pretende hacerlo. ${ }^{5}$ Se trata más bien de reapropiarse de Kant y Hegel, de recorrer una ruta que vaya de Kant a Hegel, pero cuyo destino último sea una nueva filosofía analítica.

En las siguientes páginas voy a exponer y a la vez discutir los trazos fundamentales de esa andanada filosófica. Empezaré por Kant, y más concretamente, por la deducción de las categorías, por la lectura que hace McDowell de ella y por la conexión que se establece aquí con Hegel. Pasaré entonces a tematizar el concepto de idealismo y la interpretación que hace McDowell del mismo. Y terminaré entrando en la cuestión del conocimiento empírico en Hegel y McDowell.

\section{Kant, Hegel y la deducción de las categorías}

En su ensayo Hegel's Idealism as Radicalization of Kant, McDowell da cuenta de la que es a su juicio la gran aportación de la filosofía kantiana a la filosofía teórica, pero también de sus límites, y propone, en última instancia, entender a Hegel como una superación de las limitaciones kantianas. El concepto fundamental a este respecto para McDowell, y también para Hegel, es el concepto kantiano de unidad sintética de la apercepción. Para Kant, la unidad sintética de la apercepción, también llamada unidad trascendental de la autoconciencia, está a la base de la unidad de todo juicio,

\footnotetext{
Cf. Sellars (1997), pp. 78s.

4 Cf. Rorty (1997), p. 3. También cabe encontrar en el proyecto de Sellars ciertas motivaciones hegelianas, como en el $\S 20$ de Empiricism and the Philosophy of Mind. Cf. Sellars (1997), p. 45.

5 Cf. McDowell (1996), pp. 124s.
} 
y es a través de un juicio como la diversidad de datos sensibles se unifica en un objeto. La objetividad no está por tanto simplemente dada en lo sensible, sino que, muy al contrario, la diversidad de lo sensible es sintetizada gracias a las categorías en una unidad, esto es, en un objeto. Esta unificación o conjunción de la multiplicidad es siempre, para Kant, producto de la espontaneidad del entendimiento, o como diría McDowell, de la libre actividad cognitiva. La sensibilidad no nos ofrece objetos como dados, sino que toda unidad objetiva proviene de la espontaneidad. Espacio y tiempo, como intuiciones puras, son condiciones de posibilidad del conocimiento, pero igualmente lo son las categorías. Lo que nos muestra la deducción trascendental es la validez objetiva de estas últimas: las condiciones del entendimiento son las condiciones de los objetos mismos.

Que toda objetividad tenga su raíz en la actividad intelectual autoconsciente, prosigue McDowell, abre el camino al idealismo hegeliano. ${ }^{6}$ Sin embargo, este idealismo objetivo se queda en Kant en una mera aspiración. Pues la libre actividad del entendimiento está condicionada, para Kant, por los datos de la intuición sensible. Es decir, para que haya experiencia, son necesarias las categorías del entendimiento, la espontaneidad unificadora del intelecto, pero ha de haber igualmente un material sobre el que se ejerza esa actividad: la diversidad de lo sensible ha de estar dada. Las categorías, si han de tener sentido objetivo, han de aplicarse al conocimiento empírico. De otra manera son puras formas vacías del pensar. O dicho en otros términos: conceptos sin intuiciones son vacíos. Y es en éste punto donde el idealismo trascendental de Kant se vuelve subjetivo, según McDowell. Porque lo que Kant nos ofrecería en la estética trascendental sería una teoría de cómo nuestra sensibilidad está formada. Para McDowell, igual que en su día para Husserl, la filosofía kantiana cae en último término en un psicologismo subjetivo:

In the Aesthetic, Kant tries to ground a priori knowledge on the way our sensibility is formed. [...] The harshest way to put this criticism is to say that though the Aesthetic purports to ground a priori knowledge that is objective, in the only sense we can make intelligible to ourselves, what it puts in place is indistinguishable from a subjectivistic psychologism. $^{7}$

No es mi propósito aquí discutir si esta crítica a Kant está o no justificada. Sea como fuere, para McDowell el idealismo objetivo se ve frustrado en Kant por la constricción de un psicologismo subjetivo. El avance que supone la deducción de las categorías es de esta manera abandonado debido a la exigencia de que la materia sensible esté dada, pues nuestra sensibilidad supone, en este sentido, una imposición subjetiva. El problema, para McDowell, reside en que espacio y tiempo, como intuiciones puras, son condiciones subjetivas de nuestra sensibilidad. Y la solución consiste en descartar espacio y tiempo como condiciones del conocimiento, liberar al pensamiento de su restricción sensible. Esto es lo que McDowell llama la radicalización hegeliana de Kant. $^{8}$

La radicalización de Kant es llevada a cabo por el mismo Hegel en Creer y saber. En esta obra, Hegel plantea una fundamentación de las intuiciones puras 
(espacio y tiempo) en la unidad originaria de la apercepción, extendiendo así el rol que inicialmente Kant le había otorgado a este concepto. O dicho de otra manera: Hegel ve en la unidad originaria del yo pienso no sólo el principio fundamental del entendimiento, sino el fundamento unitario y radical de entendimiento y sensibilidad. ${ }^{9}$ En Kant, toda intuición está sometida a las formas puras de la sensibilidad, es decir, es temporal y espacial. Pero para hablar de conocimiento no basta con intuiciones. En primer lugar, la diversidad intuitiva ha de ser reproductible y por tanto unificada bajo una representación, y eso sólo es posible en base a la imaginación trascendental. Pero en segundo lugar, las diversas representaciones han de ser unificadas mediante la regla aportada por un concepto en un objeto, y esta unidad categorial es posible gracias a la unidad de la apercepción. En este marco, la relectura hegeliana de la deducción de las categorías es la siguiente: espacio y tiempo, como intuiciones puras, tienen su fundamento en la imaginación trascendental, y la imaginación trascendental se fundamenta a su vez en la unidad originaria de la apercepctión o unidad de la autoconciencia. La autoconciencia es el principio único del conocimiento, principio que fundamenta tanto sensibilidad como entendimiento. Ella es la unidad originaria entre el abstracto yo pienso y el mundo dado a la intuición.

\section{La inconstricción del pensamiento}

El paso que da Hegel consiste, según McDowell, en negar la externalidad del pensamiento, esto es, en negar aquella supuesta materia independiente de toda forma conceptual que, según Kant, ha de darse a la intuición para que podamos hablar de conocimiento. Así, la ruta de Kant a Hegel desemboca, para McDowell, en una posición muy similar a la que él mismo defiende y que, con las modificaciones y correcciones que posteriormente han sido necesarias, en lo esencial está expuesta en Mind and World. ${ }^{10}$ La tesis principal de McDowell en esta obra es que las capacidades conceptuales permean la receptividad misma, que no hay nada parecido a la mera presencia de algo externo al pensamiento, y que si lo hay, esa mera presencia no puede ser la base de ningún juicio. La espontaneidad del entendimiento no es una capacidad que sólo se ejerza a partir del material aconceptual dado a la intuición, sino que en ese material mismo de la intuición, en aquello que está dado a la receptividad, están intrínsecas capacidades conceptuales. La experiencia es pasiva, pero está permeada de capacidades operacionales de la espontaneidad. ${ }^{11}$ Con esta posición,

9 Cf. Hegel (1986), TW 2, p. 305.

10 Cf. McDowell (2009), p. 89. Stephen Houlgate ha puesto en duda la interpretación de McDowell sobre Hegel en este punto. Para Houlgate, las cuestiones epistémicas que preocupan a McDowell encuentran su lugar sistemático en Hegel en la filosofía del espíritu subjetivo, precisamente una parte de la obra de Hegel que, según Houlgate, McDowell ha descuidado en sus publicaciones. Estudiando la filosofía del espíritu subjetivo, Houlgate distingue básicamente tres niveles: sensibilidad (en inglés sensation), conciencia (consciousness) e inteligencia (intelligence). Hegel atribuye a cada uno de estos niveles una función específica que aparecería desdibujada en McDowell. Y lo que es más importante aún: en el nivel más inferior, el de la sensibilidad (sensation) no se puede hablar estrictamente en Hegel de espontaneidad, sino que según Houlgate, Hegel piensa la sensibilidad como una capacidad pasiva, una pura receptividad, en línea con el pensamiento de Kant. Es decir, al nivel de la sensibilidad, el sujeto cognoscente apercibe simplemente datos aconceptuales, puramente dados y empíricos, que vienen del mundo exterior. No es determinante, sino más bien determinado. Cf. Houlgate (2006), p. 243.

1 Cf. McDowell (1996), primera lección. En su polémica con McDowell, Robert Pippin concuerda con el sin embargo en que éste es el problema fundamental: cómo pensar la unidad entre espontaneidad y receptividad, 
McDowell ofrece una salida a lo que él llama una intolerable oscilación entre el mito de lo dado y un coherentismo, como el que puede atribuirse a Donald Davidson, que corre el peligro de descartar completamente el ser de las cosas. En efecto, el error de Davidson es para McDowell su negación de cualquier rol justificador a la experiencia. Si ésta es una posición insostenible, también lo es su contraria, el afirmar que la referencia a la cruda realidad puede ser motivo para justificar algo, y entiéndase aquí por cruda realidad aquello que es lo otro de lo conceptual, una realidad dada, virgen al pensamiento. Esta segunda posición nos devolvería al mito de lo dado. La clave para McDowell es recuperar la experiencia, pero entender la experiencia no como algo dado, sino como el reflejo de lo conceptual.

Hasta aquí parecería todo muy kantiano. La diferencia hegeliana que añade McDowell, sin embargo, es la inconstricción del pensamiento, o utilizando su misma expresión: the unboundedness of the conceptual. ${ }^{12}$ Todo elemento compositor de conocimiento está permeado de pensamiento. No hay nada meramente dado, no existe esa multiplicidad dada a los sentidos y previa al entendimiento de la que habla Kant, sino que para McDowell, no hay estrictamente un afuera del pensamiento. No existe fisura ontológica entre pensamiento y realidad. Thinking catches reality in its net. Por supuesto, esto no debe entenderse en el sentido de una arbitrariedad desmesurada. En nuestro juzgar y pensar, nuestro investigar y plantear teorías, estamos, qué duda cabe para McDowell, constreñidos por los hechos. Los hechos, la realidad misma, no es producto de nuestro pensar, y no podemos de ninguna manera moldearla a nuestro antojo con sólo pensarla. Los hechos no son fruto de nuestro pensar, pero sí son susceptibles de ser englobados bajo el pensamiento. Son constricciones a nuestro pensar, pero no son nada externo al pensamiento mismo. ${ }^{13}$ Pues todo hecho, todo aquello aparentemente dado, presupone e implica en sí mismo un understanding background que lo hace posible. Gracias a esta naturaleza en sí misma conceptual, los hechos pueden figurar como razones para emitir juicios y argumentaciones. Lo que el mito de lo dado nos ofrece bajo la apariencia de razones empíricas son exculpaciones, pues algo totalmente aconceptual, una materia amorfa, puede ser quizá una causa material de otra cosa, pero no puede ser nunca una razón. Si algo es razón de algo, si algo justifica un juicio, si la experiencia ha de demostrar algo, es porque no es independiente de lo conceptual. O como explica McDowell, lo conceptual no es un subconjunto del espacio de las razones, es decir, no hay razones que no sean conceptuales: el espacio de las razones y el espacio de los conceptos son equipotentes. Se puede hacer y de hecho hacemos constantemente referencia a los hechos para justificar nuestros juicios, pero con ello no señalamos nada otro, sino algo pensable, algo que está ya de por sí englobado bajo el pensamiento. ${ }^{14}$

La espontaneidad permea la experiencia e integra un hecho concreto en el todo de un mundo pensable. El criterio de verdad, dentro de este marco filosófico planteado por McDowell, no es la comparación de nuestro pensamiento con algo externo a él, sino nuestra capacidad autocrítica, la labor reflexiva constante de corrección y perfeccionamiento. ${ }^{15}$ Este desarrollo autocrítico tiene lugar dentro de los márgenes

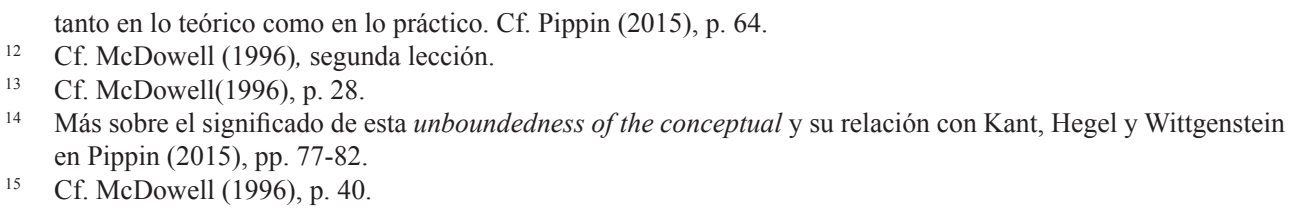


del pensamiento, pues el pensamiento como tal no tiene constricción externa alguna, no hay nada fuera de él, ni él reconoce como criterio nada más que sí mismo. Y ésta es una idea central del idealismo de Hegel, como McDowell con mucha razón señala:

It is central to Absolute Idealism to reject the idea that the conceptual realm has an outer boundary, and we have arrived at a point from which we could start to domesticate the rhetoric of that philosophy. Consider, for instance, this remark of Hegel's: «In thinking, I am free, because I am not in an other.» This expresses exactly the image I have been using, in which the conceptual is unbounded; there is no outside it. ${ }^{16}$

Aquí culmina el tránsito de la filosofía analítica de Kant a Hegel de la mano de McDowell. Y es precisamente ésta una cuestión decisiva en la discusión entre Kant y Hegel. Volvamos a Glauben und Wissen. El gran logro de la filosofía kantiana, mantiene Hegel allí, es haber demostrado el idealismo. ${ }^{17}$ La lectura hegeliana de la deducción de las categorías entiende que la autoconciencia pura es la fuente de toda verdad y toda objetividad. La crítica kantiana ha mostrado para Hegel la objetividad del pensamiento: lo empírico tiene sustento y es objeto, esto es, tiene objetividad, sólo gracias a la síntesis del pensamiento. Kant ha demostrado, por tanto, que la unidad de todo objeto se reduce a la unidad del pensar, que lo otro del pensar, materia amorfa previa, es nulo en sí mismo, que no tiene consistencia alguna, que, por el contrario, todo aquello que tiene de objetividad y verdad lo adquiere gracias al pensamiento. Pero este pensar, para Hegel, no es el yo, no es ningún tipo de subjetividad. Y, por supuesto, está más allá de la subjetividad finita de un individuo. El mismo Kant mantiene esto en la medida en que critica el idealismo de Berkeley. ${ }^{18}$ Sin embargo, en la medida en que insiste en que ha de haber algo dado a la sensibilidad para hablar de conocimiento, limita el pensamiento a lo subjetivo y lo enfrenta de nuevo con lo objetivo. Por esta razón afirma Hegel años después en la Enciclopedia que toda la filosofía kantiana está en el fondo englobada en la doctrina de la conciencia. ${ }^{19}$ El idealismo kantiano, como bien destaca McDowell, da un paso atrás respecto al resultado de la deducción trascendental y se limita a un idealismo subjetivo, o como diría Hegel, finito.

De facto, empero, Kant ha mostrado que toda verdad y objetividad residen en el pensamiento. Por eso, aquello que sea lo empírico más allá del pensar, aquello que lo otro del pensar pueda aportar, no tiene ningún valor para la filosofía. El mismo Kant, entiende Hegel, desacredita este conocimiento de la experiencia, esto es, en el sentido de la unión entre entendimiento y sensibilidad, en la medida en que declara que éste es sólo un conocimiento de fenómenos. La filosofía, por tanto, ha de liberarse de los fenómenos, ha de abandonar lo finito, ha de despreocuparse de la burda realidad, que no tiene ningún valor en sí misma, y volcarse al conocimiento de las ideas, es más, al conocimiento de la Idea. La filosofía, para Hegel, es idealismo, o no es filosofía alguna. Y por idealismo entiende Hegel lo siguiente: „El idealismo de la filosofía no consiste en otra cosa que en no reconocer lo finito como un ente verdadero." ${ }^{\text {20 }}$

\footnotetext{
Cf. McDowell (1996), p. 44. En contra de esta interpretación "conceptualista" de Hegel, véase Wolf (2019).

Cf. Hegel (1986), TW 2, p. 303.

Cf. Kant (1974), Kritik der reinen Vernunft, B 274-279.

Cf. Hegel (1986), TW 10, § 415, nota.

„Der Idealismus der Philosophie besteht in nichts anderes als darin, das Endliche nicht als ein wahrhaft Seiendes anzuerkennen.“ Hegel (1986), TW 5, p. 172.
} 
Lo único verdadero para la filosofía es el pensamiento. No en vano es la lógica especulativa como ciencia del pensar y sus determinaciones la disciplina fundamental de la filosofía, esto es, la metafísica. El pensamiento, en tanto que autodeterminado y conocido a sí mismo como Idea absoluta, es el único objeto de estudio y contenido de la filosofía. La metafísica en Hegel no es por tanto una ciencia general de lo dado, porque lo dado, en sí mismo, no tiene valor filosófico alguno. La lógica especulativa trata más bien del pensar y sus determinaciones, que ya no son categorías, como lo fueran en Kant, porque no se refieren a objeto alguno. En la medida en que la verdad de todo objeto está en el pensar, el paso que realiza Hegel con respecto a Kant es dejar de lado tanto la subjetividad como aquel supuesto mundo externo y centrarse en el pensar y sus determinaciones en y por sí mismas, sin referencia a objeto o sujeto alguno. ${ }^{21}$

He aquí, empero, un aspecto que se encuentra bajo mi punto de vista desatendido en el pensamiento de McDowell, y quizás en base a buenas razones. McDowell recupera a Hegel para tomar posición en los debates contemporáneos de la filosofía analítica. Pero la filosofía analítica contemporánea, vista desde la filosofía de Hegel, parece estar encerrada en la dialéctica de la conciencia y su objeto. La mente y el mundo es, dicho grosso modo, el gran tema de la Fenomenología del espíritu. Pero es precisamente esa oposición la que Hegel quiere dejar atrás con su filosofía, la que, en su opinión, después de la deducción trascendental de Kant ha de ser superada. McDowell, sin embargo, se sitúa en la perspectiva del individuo y su conocimiento del mundo que le rodea, y esto implica cierta decepción para el lector. Lo conceptual no tiene límites; hay que abandonar el mito de lo dado, según McDowell: nuestras capacidades cognitivas están ya en juego en nuestra receptividad, en todo lo que nos es dado como hechos. A partir de aquí, el planteamiento gira en torno a pensar el ser humano como un animal racional, como un animal en cuyo ser mismo está intrínseca la espontaneidad del pensar y el actuar, una espontaneidad que no le sitúa en un mero entorno, como al resto de animales, sino en un verdadero mundo en el que pensar y ejercer su libertad. Entre este mundo y el yo no hay fisura ontológica alguna, pues ambos, mundo e individuo, están permeados por la espontaneidad del pensamiento. Y esta espontaneidad del pensamiento no es un don divino inexplicable del ser humano, sino el producto de la madurez. Los seres humanos nacen siendo meros animales, pero la educación - aquí McDowell hace referencia al término alemán Bildung - convierte nuestra naturaleza o hace incluso que alcancemos nuestra verdadera naturaleza: nos transforma de meros animales en personas que piensan y actúan. En este proceso de aprendizaje, en esta Bildung, la adquisición del lenguaje juega un papel fundamental, pues con ella se posibilita nuestra entrada en el espacio de las razones. ${ }^{22}$

McDowell recupera Aristóteles para volver a pensar el ser humano como la combinación de naturaleza y razón, como un animal racional, en cuya naturaleza reside la espontaneidad del pensar y actuar. Lo hace en base a su tránsito de Kant a Hegel, a la radicalización que Hegel representa respecto a Kant. Pero la radicalidad de Hegel va, desde mi punto de vista, mucho más allá de lo que McDowell plantea. Uno puede tomar, como hace McDowell, el idealismo hegeliano en el sentido de

21 Para la revolución en el concepto de verdad llevada a cabo por Hegel, cf. el clásico trabajo de David Stern (1991).

22 Cf. McDowell (1996), sexta lección. 
que lo conceptual está presente en todo lo que hay, que nada escapa a su infinita red. Pero, estrictamente, Hegel plantea el sentido contrario: el pensamiento es lo verdadero en y para sí, y en su formación más acabada como Idea absoluta, es lo verdadero y todo lo verdadero. Todo lo demás que pueda haber y hay más allá del pensamiento, aquello que es exterior a la Idea, es nulo, insignificante, es totalmente irrelevante para la verdad filosófica. Lo que Hegel plantea, por tanto, no es que podamos estar tranquilos y a salvo de la duda escéptica respecto al conocimiento del mundo, sino otra cosa muy diferente y mucho más radical: que debemos despedirnos del mundo, que debemos elevarnos de lo finito y mundano al éter del pensar puro y sus determinaciones, porque ahí reside la verdad. Y ésa es en efecto la función de la Fenomenología del espíritu, a saber, elevar al individuo al éter del saber.

\section{La experiencia y el libre movimiento del concepto}

Así pues, la radicalización que hace Hegel de la filosofía kantiana es mucho mayor de lo que plantea McDowell. Y sin embargo, no es menos cierto que la filosofía según Hegel no se limita a la ciencia del pensar y sus determinaciones. Si bien en eso consiste la metafísica qua lógica especulativa, el sistema de la filosofía tiene también otras dos partes: las filosofías de la naturaleza y del espíritu. ${ }^{23}$ En ocasiones, Hegel engloba ambas bajo la denominación de 'filosofía real' en contraposición a la Lógica. Si bien la filosofía hegeliana plantea una elevación al éter del pensar y sus determinaciones, no es menos cierto que implica después un descenso a la realidad y una reflexión filosófica sobre ella. La realidad, por tanto, juega un papel en el sistema hegeliano, y la cuestión es entonces saber cuál. Pero antes de entrar a ver en qué consiste ese papel y cómo se relaciona el libre movimiento del concepto con el desarrollo de la investigación empírica, es necesario atender previamente con precaución y minuciosidad a las distinciones que hace Hegel a este respecto. Me refiero a la triple distinción entre realidad, realidad efectiva y objetividad (en alemán: Realität, Wirklichkeit y Objektivität).

La Ciencia de la lógica distingue tres determinaciones diferentes para lo que en el lenguaje coloquial denominamos realidad. Aquí no es necesario que entremos en completo detalle en cada una de ellas, pero sí que tengamos claro lo esencial de la distinción. Estas tres determinaciones pertenecen respectivamente a cada una de las tres esferas de la lógica especulativa. Así, la mera realidad, en alemán Realität, se desarrolla al principio de la lógica del ser y hace referencia a un ser determinado, esto es, un ser que ya no es simple y llanamente ser, como al principio de la Lógica, sino que ha adquirido una determinidad. Se trata por tanto, de un ser-ahí o estar (Dasein). El estar, por ser determinado, tiene ya una negación, y posee de esta manera una cualidad. Y en este sentido de ser determinado, de ser-ahí o estar, habla Hegel de realidad. Algo que es real es por tanto algo que está ahí, un simple ser con determinidad, un estar; ni siquiera se trata, en sentido estricto, de un algo, pues algo es la determinación inmediatamente posterior que implica también un otro. Lo real es pura y simplemente ser-ahí, sin mayor contenido. ${ }^{24}$

\footnotetext{
Cf. Fulda (2012).

24 Cf. Hegel (1986), TW 5, p. 118.
} 
Distinta de la mera Realität es la Wirklichkeit, esto es, la realidad efectiva. Wirklichkeit, además de ser el título que engloba toda la última sección de la lógica de la esencia, es una determinación generada después de la determinación de lo absoluto. Formalmente, la realidad efectiva no es más que la otra cara de la posibilidad. Realmente - así se expresa Hegel: reelle Wirklichkeit - la realidad efectiva es, como recoge el término castellano, efectiva, esto es, produce un efecto. En alemán, Hegel recoge esta idea con el término Wirklichkeit y su proximidad a wirken, surtir efecto. Lo realmente efectivo (wirklich), por tanto, no es algo que esté simplemente ahí, sino algo que se manifiesta mediante sus efectos. Así, la posibilidad real de algo es el conjunto de factores que lo traen, diríamos, materialmente a la existencia. E igualmente, en tanto que algo realmente efectivo, producirá a su vez algo nuevo. En este sentido de realidad como realidad efectiva ha de hablar normalmente la filosofía según Hegel. ${ }^{25}$

Por último, diferente de estas dos últimas, está la objetividad (Objektivität) ${ }^{26} \mathrm{Su}$ desarrollo pertenece a la lógica del concepto y engloba toda una serie de subdivisiones, como son la más general entre mecanismo, quimismo y teleología. En todo esto no voy a entrar aquí, sino que voy a intentar dar la idea general de objetividad en sentido estricto según Hegel - hasta ahora habíamos hablado de objetividad en el sentido laxo de ser un objeto (Gegenstand). La objetividad no puede equipararse ni a la realidad ni a la realidad efectiva. De entrada, la primera idea que hay que retener es que la objetividad, en Hegel, es siempre la objetividad del concepto. La objetividad es un momento en el desarrollo del concepto en su completarse hasta ser idea. En este desarrollo, la objetividad es el momento del ser-ahí del concepto, su realización. Profundizando más, lo fundamental del concepto hegeliano de concepto es la idea de una universalidad concreta que encierra en sí misma particularidad e individualidad. La universalidad es normalmente concebida como el resultado de un proceso de abstracción. Lo universal suele ser así propiedad común de muchos, el género. Añadiendo una diferencia específica, esto es, algo más, se obtiene la especie, o lo particular. Lo individual es finalmente lo que encierra más contenido y diferencias respecto a todo lo demás.

La universalidad que piensa Hegel con el concepto es, por el contrario, una universalidad concreta. En el concepto, particularidad e individualidad no se contraponen a lo universal, sino que son más bien su desarrollo (Entwicklung). En su desarrollo, el concepto despliega sus determinaciones sin que tope con nada que no sea él mismo, es decir, sin que encuentre nada nuevo, sino que solamente hace explícito lo que antes ya estaba implícito. Dado que particularidad e individualidad están contenidas en la universalidad del concepto, es más, dado que ambas no son ni más ni menos que el desarrollo de esta universalidad, llegamos a la clave del asunto: al concepto le pertenece esencialmente su autoconcreción, o dicho de otro modo, la universalidad del concepto se individualiza, igual que esta individualidad es esencialmente universal. Y el concepto, por tanto, se expone en lo real, se otorga a sí mismo un ser-ahí. ${ }^{27}$ Este ser-ahí del concepto es su objetividad, su presencia

\footnotetext{
Cf. Hegel (1986), TW 6, p. 208.

Cf. Hegel (1986), TW 6, p. 402ff.

Exponer significa en alemán darstellen. Miriam Wildenauer ha mostrado lúcidamente como en la idea hegeliana de una exposición del concepto (Darstellung des Begriffs) está asumido el sentido kantiano del término Darstellung. Cf. Kant (1974), Kritik der Urteilskraft, p. 103, B XLIX / A XLVII. En este sentido, exponer un concepto es mostrar una intuición correspondiente. Exponer el concepto de concepto es mostrar una realidad
} 
en lo real. Su desarrollo a partir de entonces consiste en lograr la adecuación de su objetividad consigo mismo. El culmen de esta evolución se alcanza con la unidad de concepto y objetividad: la Idea. En la medida en que el concepto consigue exponerse totalmente en lo real se convierte en Idea. En este marco, el todo orgánico, caracterizado fundamentalmente por su finalidad intrínseca, es la exposición objetiva más completa del concepto especulativo.

Valga lo dicho como caracterización general de la objetividad en Hegel, sabiendo siempre que este tema requeriría profundizar mucho más. Como vemos, la objetividad no es sustituible por el término realidad en general, ni por el de realidad efectiva. La objetividad es el ser-ahí del concepto, su realización. Lo meramente real no es objeto del concepto. Tampoco lo que posee realidad efectiva es de por sí exposición del concepto. La objetividad del concepto es, claro está, un ser-ahí. Es incluso una realidad efectiva. Pero es esencialmente exposición del concepto, y como tal sus determinaciones han de ser la exteriorización de las determinaciones del concepto. Y aquí está el punto que interesa resaltar. No todo lo que meramente es, ni tampoco todo lo que tiene una existencia material y efectiva, es exposición del concepto. La realidad en su conjunto no es la objetividad del concepto, pero ciertas realidades sí pueden ser la exposición objetiva de lo racional. Esto concuerda claramente con el sentido que le da Hegel al idealismo: no se trata de hacer una categorización de lo real, ni tampoco importa a la filosofía cómo sea la realidad en sí. En y de por sí, tampoco importa la realidad pensada como Wirklichkeit, esto es, como realidad efectiva. A la filosofía, al menos pensada como sistema, lo que le interesa es la Idea, esto es, el conocimiento de lo racional tanto en el elemento del pensar como en su exposición concreta en lo real.

Éste último punto, importantísimo en Hegel, aparece desdibujado en McDowell. Al afirmar la ilimitación de lo conceptual, la presencia de lo conceptual ya en toda experiencia concreta, en todo hecho y en todo lo 'dado', McDowell concluye entendiendo que la experiencia no es ni más ni menos que un momento en lo que en Hegel sería el desarrollo del concepto. Corrigiendo a Robert Pippin, McDowell expone su interpretación de Hegel en este sentido:

The picture is rather on these lines. 'The Notion' (singular) is conceptuality as such, properly understood. Conceptuality as such is categorial, in a more or less Kantian sense that we can gloss in terms of apperceptive spontaneity. Conceptual capacities are essentially such as to be exercised in judgment. Hegelian talk of 'the Notion' does not allude to special non-empirical concepts about which an issue would arise about how they relate to ordinary empirical concepts. [...] Talk of «the free movement of the Notion» fits, for instance, the evolution of empirical inquiry. (This is the right instance to begin with if we approach Hegelian thinking from Kant's Deduction.) And empirical inquiry is guided by experience. ${ }^{28}$

La concepción propia de McDowell, que tiene un valor filosófico intrínseco independientemente de Kant o Hegel, dista en este punto en concreto de la posición hegeliana en dos cuestiones a mi parecer fundamentales. La primera es la ausencia

que lo encarne. En la Ciencia de la lógica, la exposición más inmediata del concepto es la idea de la vida. Cf. Wildenauer (2003), p. 54.

28 McDowell (2009), p. 86. 
de la distinción que hemos visto entre realidad, realidad efectiva y objetividad, que le lleva a afirmar que la experiencia y la investigación empírica son un momento del desarrollo del concepto. La segunda, entrelazada con esta, es la desatención a la diferencia que hace Hegel entre el conocimiento de las ciencias y el conocimiento estrictamente filosófico, y que este desarrolla sobre todo en su doctrina de la Idea, al final de la Lógica.

La triple distinción entre realidad, realidad efectiva y objetividad adquiere enorme relevancia cuando McDowell plantea la tesis de que la experiencia, en el sentido de investigación empírica, es un momento del movimiento libre del concepto. Huelga decir aquí que estamos hablando de experiencia en este sentido y no del concepto de experiencia de la conciencia propio de la Fenomenología del espíritu. ${ }^{29}$ La investigación empírica es labor de las ciencias, tanto en nuestra época como ya en tiempos de Hegel. Las ciencias investigan la realidad dividida en diferentes campos que corresponden a las diferentes ciencias naturales y sociales. Lo cual no quiere decir ni que sean capaces de agotar la realidad ni que no haya ciencias, como las matemáticas, que tengan un status especial. Sea como fuere, la investigación empírica es conocimiento de la realidad, y sobre todo, de lo que Hegel llama la realidad efectiva, esto es, no simplemente de lo que hay o es, sino de lo que produce efectos en su entorno y es explicable bajo leyes.

Ahora bien, el libre movimiento del concepto es el transcurso de éste desde sí mismo a través de su objetividad hasta la adecuación de esta objetividad consigo mismo. Se trata del camino que se articula en los tres momentos respectivos de la universalidad del concepto, su objetividad y su culminación como Idea. ¿Qué papel juega en todo esto la experiencia? Objetividad no es realidad, ni siquiera realidad efectiva. La experiencia, por tanto, como investigación empírica sobre la realidad, no es por sí sola un momento del libre movimiento del concepto. De hecho, concepto, objetividad e Idea se desarrollan argumentativamente en la Ciencia de la lógica sin que sea necesario recurrir al conocimiento empírico. Y, sin embargo, es bien cierto que la filosofía de Hegel no se limita al puro conocer lógico del pensar y sus determinaciones. Como sistema, su filosofía tiene otras dos ciencias filosóficas, filosofías, qué duda cabe, de lo real. Esto conecta con la segunda cuestión que he planteado, a saber, la del conocimiento filosófico a diferencia y en relación con el conocimiento científico en Hegel.

La distinción entre conocimiento científico y conocimiento filosófico es desarrollada en la doctrina de la Idea, al final de la Ciencia de la lógica. Kant ya había reclamado un método específico de conocer para la filosofía, que no podía asumirse de otras ciencias. Su caracterización del conocimiento filosófico como conocimiento racional a partir de conceptos quedó, sin embargo, sin ulterior desarrollo. ${ }^{30}$ En la Lógica, Hegel asume la tarea de delimitar y definir claramente el conocimiento filosófico. En contraste con el conocer filosófico, las ciencias ofrecen un conocer finito, cuyo esquema general está expuesto en la Idea de lo verdadero, dentro de la Idea del conocer. La idea del conocer en general, que engloba conocer teórico y práctico (Idea de lo bueno), se caracteriza por un dualismo supuestamente irreconciliable entre concepto y mundo. En el caso del conocer teórico, la aspiración que está en juego es conocer la verdad del mundo. Se trata de la contraposición entre un

\footnotetext{
Cf. McDowell (2009), p. 88.

30 Cf. Kant (1974), Kritik der reinen Vernunft, B 742 / A 714.
} 
mundo aparentemente dado, donde reside la verdad, y una subjetividad cognoscente que para el conocimiento es en sí misma irrelevante. La filosofía especulativa muestra que esta visión es superable, en la medida en que la esencia de subjetividad y mundo dado es una y la misma, la razón. Pero las ciencias, en su conocimiento del mundo, se sitúan en esta perspectiva. Su afán es registrar y entender lo real. Y su conocimiento puede seguir, según Hegel, dos tipos de proceder: analítico y sintético. No es necesario que entremos aquí detalladamente en esta distinción. Baste decir que, mientras el conocimiento sintético parte de un concepto universal, entendida esta universalidad de manera abstracta, y desarrolla a partir de éste definiciones y clasificaciones, el conocimiento analítico consiste en concebir la multiplicidad en su unidad. Parte, por tanto, de lo concreto y culmina en lo universal, también entendido éste como universal abstracto, como lo común a muchos.

Habría que entrar más a fondo a desarrollar esta distinción, pero eso requiere una investigación propia. ${ }^{31}$ Lo importante ahora mismo es señalar que ninguno de estos dos procederes de conocer son propios de la filosofía según Hegel. La filosofía tiene para Hegel un único objeto y contenido: la Idea absoluta. ${ }^{32}$ El conocimiento filosófico se corresponde, por ello, con el autoconocimiento de la Idea. El proceder de este conocer está expuesto en el método especulativo, en el capítulo sobre la Idea absoluta. Éste método especulativo, como tal, no es un método de investigación científica, ni tampoco un método de exposición de los resultados de la investigación científica. No se trata de un método de conocimiento universal, como muchas veces se ha interpretado. Lo que Hegel plantea es un método de conocimiento genuinamente filosófico, esto es, un método de conocimiento de la idea absoluta, que es a su vez una descripción de lo esencial del autoconocerse de la idea misma, lo verdadero por excelencia.

El método especulativo es lo que propiamente llama Hegel el libre movimiento del concepto. Aquí, nuevamente, haría falta una exposición específica de este tema. Pero podemos dar unas pinceladas. En su proceder, el conocer filosófico comienza siempre desde lo más simple e inmediato. Pero no se trata de lo inmediato de la experiencia, que en sí mismo es más bien un complejo de múltiples determinaciones, sino de lo inmediato y simple del pensar. En el pensar, lo más simple e inmediato es lo más abstracto, lo que contiene menos determinaciones o, lo que es lo mismo, lo que tiene una determinación más pobre. En el caso de la Lógica, por ejemplo, el comienzo es con el ser - puro ser, sin mayor determinación. Este comienzo da paso a un segundo momento, el momento del juicio, o también llamado por Hegel el momento dialéctico. Lo inmediato y abstracto, precisamente por su simpleza, anima a pensar. Y en efecto, enseguida se revela como algo mediado, algo que para tener sentido precisa de algo otro. Lo universalmente abstracto se concreta, lo simple deviene complejo y lo 'uno' requiere esencialmente de un 'otro'. Se entra así en la esfera de la objetividad, en el ser-ahí del concepto, en la diferencia. La última fase es la unidad de universalidad e individualidad, el reconocimiento del concepto en su objetividad gracias a su universalidad esencialmente concreta. Con ella, el conocer filosófico se eleva a la idea por excelencia. En conjunto, el proceder filosófico expone la universalidad de la razón en la particularidad de la objetividad, mostrando que lo universal es también concreto, que lo libre es realizable aquí y ahora.

Más sobre la epistemología contenida en la lógica de la Idea en Fulda (2004).

Cf. Hegel (1986), TW 6, p. 549. 
La filosofía, en tanto que autoconocimiento de la Idea absoluta en un sistema, procede siguiendo este esquema. $\mathrm{Su}$ inicio es la lógica especulativa, situada en el elemento del pensar y sus determinaciones, en la universalidad de la idea. Filosofía de la naturaleza y filosofía del espíritu exponen la Idea absoluta en su otro, en la objetividad, si bien la filosofía del espíritu se caracteriza precisamente por la vuelta paulatina de la idea a sí misma. Y es en ambas filosofías reales donde el concepto de experiencia tiene un papel fundamental, si bien no en el sentido estricto de momento del libre movimiento del concepto, como afirma McDowell. Pasemos a ver esta última cuestión.

\section{Experiencia y sistema}

El papel de las filosofías de la naturaleza y el espíritu en Hegel es una cuestión de entrada compleja. La dificultad reside en hacer justicia al hecho de que, estrictamente, ni son propiamente metafísica, ni son propiamente ciencia. Muy al contrario de la opinión comúnmente extendida, lo cierto es que no toda la filosofía de Hegel se enmarca dentro de la metafísica. Ni la totalidad del sistema de Hegel es metafísica, ni la totalidad de su filosofía, si entendemos la Fenomenología del espíritu de 1807 como una filosofía que propiamente se sitúa fuera del sistema, es metafísica. ${ }^{33} \mathrm{La}$ metafísica tiene en Hegel un lugar específico y claramente definido. Metafísica es en Hegel única y exclusivamente la lógica especulativa. Y la lógica especulativa es metafísica en el doble sentido de filosofía primera y última. Como filosofía primera, la lógica fundamenta las otras dos ciencias filosóficas de la naturaleza y del espíritu. Como filosofía última, la lógica es el último tema de la filosofía sistemática, o mejor dicho, la última tematización del único contenido de la filosofía, a saber, la Idea absoluta, que después de todo el recorrido del sistema vuelve a sí, en tanto que espíritu absoluto, en la forma de la filosofía, esto es, en la forma del pensar que se piensa a sí mismo.

Entre medias se ubican las dos disciplinas de lo que se puede englobar nominalmente como filosofía real. Digo nominalmente, porque las filosofías de la naturaleza y del espíritu no están unificadas en un género superior, una especie de filosofía cuyo ámbito sea lo real, porque lo real, como tal, no es tema de la filosofía en sentido sistemático. Es decir, la división fundamental del sistema hegeliano es tripartita, y no bipartita. En cualquier caso, filosofía de la naturaleza y filosofía del espíritu son eso, simplemente filosofías, y no metafísicas de la naturaleza y del espíritu. Y tampoco son ciencias a secas, sino ciencias filosóficas, que en ningún caso pretenden sustituir a las ciencias comunes, sino más bien al contrario: precisan de ellas en su filosofar. Filosofía de la naturaleza y filosofía del espíritu se sitúan, así, entre metafísica y ciencias.

¿Qué papel juega entonces la experiencia, como investigación empírica, en el sistema de la filosofía de Hegel? Cualquier lectora o lector conoce el enorme conocimiento de las ciencias, la historia y la política que poseía él mismo y que se refleja en numerosas partes de su obra. Hegel hace referencia en múltiples ocasiones a los resultados de la ciencia de su época, a teorías químicas, físicas, o matemáticas, además de al derecho o la historia en el ámbito del espíritu. Pero esto, por sí sólo, no

33 Cf. Fulda (2012). 
significa nada. Bien podría ser que Hegel, para ejemplificar o dar plausibilidad a un razonamiento ya hecho de antemano, a priori e independientemente de las ciencias, echara mano de ciertos resultados científicos que encajan en el desarrollo de su línea argumental. La cuestión fundamental es, sin embargo, que los resultados de las ciencias juegan un papel crucial, que sin ellas no hay filosofía de la naturaleza ni del espíritu posibles.

Si tomamos la filosofía de la naturaleza, quizá la esfera en la que la relación entre ciencia y filosofía en Hegel pueda estar bajo mayor sospecha, nos encontramos con que no sólo la filosofía no procede aquí de ninguna manera independientemente de la ciencia, sino que más bien al contrario, procede en colaboración con ella. La filosofía es reflexión sobre los resultados que la ciencia en su investigación empírica suministra. La ciencia natural por excelencia en los tiempos de Hegel era la física newtoniana, y sobre la relación entre física y filosofía de la naturaleza leemos en los Zusätze de la Enciclopedia:

La filosofía de la naturaleza retoma el material que la física le proporciona a partir de la experiencia en el punto mismo al que la física lo ha llevado y lo reestructura, sin dar a la experiencia el carácter de criterio último. ${ }^{34}$

Una diferencia fundamental entre la metafísica hegeliana o lógica especulativa y la filosofía de la naturaleza (y también con la filosofía del espíritu) reside en que la última trabaja con un material que procede de lo empírico. Así, la filosofía de la naturaleza reflexiona, como vemos, sobre los últimos resultados de la ciencia; se sitúa en el campo de conocimiento de la ciencia más avanzada y, precisamente allí, en el límite de la ciencia misma, es donde comienza su reflexión. La filosofía retoma el material aportado sin tener en cuenta ya a la experiencia como criterio último. En efecto, la experiencia, como he señalado más arriba, nos aporta información sobre lo real. Pero la filosofía trata sin embargo de lo objetivo, esto es, de aquello que constituye el ser-ahí de la razón. Además, si bien las teorías científicas están contrastadas por la experiencia, ellas mismas son teorías, compuestas por conceptos, principios y razonamientos, y es precisamente con todo este cuerpo teórico con lo que trabaja la filosofía. Este material teórico es reestructurado - el verbo alemán es umbilden - de acuerdo con la lógica propia de la razón que, como idea, se conoce a sí misma en lo real.

Por tanto, vemos cómo, si bien la experiencia en sí misma no es un momento en el desarrollo libre del concepto, tesis que encontramos en McDowell, sí es la fuente de conocimiento científico sobre el cual la filosofía reflexiona. La filosofía razona sobre los resultados de las ciencias, en los límites de las ciencias. ${ }^{35}$ Pero éste no es un simple pensar arbitrariamente, ni mucho menos se deja la filosofía llevar por las últimas modas científicas, que como en otras esferas de lo humano, a veces van y vienen. La filosofía se beneficia de las ciencias, asume sus conocimientos y los reestructura en un sistema de la razón, los reconcibe como el autoconocerse de la Idea absoluta en naturaleza y espíritu, esto es, como el proceso de la razón universal que se piensa a sí misma.

\footnotetext{
34 Hegel (1986), TW 9, p. 20. Original alemán: „Die Naturphilosophie nimmt den Stoff, den die Physik ihr aus der Erfahrung bereitet, an dem Punkte auf, bis wohin ihn die Physik gebracht hat, und bildet ihn wieder um, ohne die Erfahrung als die letzte Bewährung zugrunde zu legen.“

35 Cf. Wahsner (1996).
} 


\section{Conclusión}

McDowell no es Hegel, ni tiene porqué serlo, pero con su obra se da el paso de Kant a Hegel en el amplio marco de la filosofía analítica, si bien dentro de este marco el giro hegeliano no deja de estar localizado en un número relativamente reducido de autores como él, Pippin o Brandom, entre otros. Pero además, el pensamiento de McDowell constituye un puente intelectual que comunica la tradición analítica y la filosofía continental, las cuales parecen no haber superado aún el cisma que las separa y se muestran todavía hoy a menudo incapaces de comprenderse mutuamente.

Nótese la distancia recorrida por la filosofía analítica desde tiempos de uno de sus precursores, Rudolf Carnap. Si lo dado es un mito y el fundamento último del saber ya no son proposiciones empíricas que describen hechos inmediatos, el primer proyecto emprendido en La construcción lógica del mundo parece derrumbarse como un castillo de naipes. Pero no sólo eso. Con la recuperación que hace McDowell de la filosofía hegeliana la discusión filosófica analítica se abre a nuevas perspectivas. La tradición analítica desterró inicialmente ya desde Carnap a la metafísica del campo filosófico con la mayor contundencia posible. El lugar de la metafísica como disciplina fundamental lo ocupaba, desde el giro lingüístico, el análisis del lenguaje. No obstante, en las últimas décadas la problemática de la metafísica en el sentido de la ontología más tradicional ha retornado en la filosofía analítica: definir lo que es el caso, los objetos y estados de cosas que conforman el mundo, establecer una teoría de lo real y de los mundos posibles. En este sentido, la vuelta a Hegel de la mando de autores como McDowell o Robert Brandom constituye una verdadera innovación para la filosofía analítica actual. Pues la metafísica hegeliana no trata ya de establecer una teoría fundamental de lo real, de los tipos fundamentales de cosas que existen y de la base ontológica de todo lo dado. Hegel concibe la metafísica, al contrario, como lógica especulativa, como el desarrollo del pensar puro y sus determinaciones. La metafísica en Hegel no es una metafísica de lo ente, sino una metafísica de la razón y la libertad, y ésa es para él la base de la filosofía. Despegarse de lo finito y mundano y elevarse al conocimiento de lo racional y lo libre es un paso fundamental en Hegel, y con el pensamiento de McDowell ese paso está cada vez más cerca.

\section{Referencias bibliográficas}

deVries, W. A. (2019): "Hegel and Sellars on the Unity of Things", International Journal of Philosophical Studies, 27:3, pp. 363-378.

Fulda, H. F. (2004): "Hegels Logik der Idee und ihre epistemologische Bedeutung", en Halbig, C. (ed.), Hegels Erbe, Frankfurt am Main, Suhrkamp, pp. 78-137.

Fulda, H. F. (2012): "La philosophie de Hegel - avec la métaphisique et sans elle", en Kervégan, J-F. (ed.), Hegel au présent. Une relève de la métaphysique?, Paris, CNRS, pp. 93-127.

Hegel, G. W. F. (1986): Werke in zwanzig Bände. Herausgegeben von Eva Moldenhauer und Karl Markus Michel (Theorie Werkausgabe), Frankfurt am Main, Suhrkamp.

Houlgate, S. (2006): "Thought and Experience in Hegel and McDowell", European Journal of Philosophy, 14, pp. 242-261.

Kant, I. (1974): Werke in zwölf Bände. Herausgegeben von Wilhelm Weischedel, Frankfurt am Main, Suhrkamp. 
McDowell, J. (1996): Mind and World, Cambridge and London, Harvard University Press.

McDowell, J. (2009): "Hegel's Idealism as a Radicalization of Kant", en McDowell, J., Having the World in View. Essays on Kant, Hegel and Sellars, Cambridge and London, Harvard University Press, pp. 69-89.

Pippin, R. (2015): “John McDowell's Germans”, en Pippin, R., Interanimations. Receiving Modern German Philosophy, Chicago and London, The University of Chicago Press, pp. 63-90.

Rorty, R. (1997): "Introduction", en Sellars, W., Empiricism and the Philosophy of Mind, Cambridge and London, Harvard University Press, pp. 1-12.

Sellars, W. (1997): Empiricism and the Philosophy of Mind, Cambridge and London, Harvard University Press.

Stern, D. (1991): "Foundationalism, Holism or Hegel?", Journal of the British Society for Phenomenology, 22:1, pp. 21-32.

Wahsner, R. (1996): Zur Kritik der Hegeschen Naturphilosophie. Über ihren Sinn im Lichte der heutigen Naturerkenntnis, Frankfurt am Main, Peter Lang.

Wildenauer, M. (2003): Epistemologie freien Denkens. Die logische Idee in Hegels philosophie des endlichen Geistes, Hamburg, Felix Meiner Verlag.

Wolf, C. W. (2019): “The Myth of the Taken: Why Hegel is not a Conceptualist”, International Journal of Philosophical Studies, 27:3, pp. 399-421. 